WSRC-TR-92-42-089

\title{
REACTOR COMPONENTS P-11/K-15 RE-INSPECTION STANDARDS (U)
}

by J. J. Banks

WSRC-TR--92-42-089

DE93 005520

Westinghouse Savannah River Company

Savannah River Site

Aiken, South Carolina 29808

Other Authors:

This paper was prepared in connection with work done under Contract No. DE-AC09-89SR18035 with the U.S. Department of Energy. By acceptance of this paper, the publisher and/or recipient acknowledges the U.S.

Government's right to retain a nonexclusive, royalty-free license in and to any copyright covering this paper, along with the right to reproduce and to authorize others to reproduce all or part of the copyrighted paper. 


\section{DISCLAIMER}

This report was prepared as an account of work sponsored by an agency of the United States Government. Neither the United States Government nor any agency thereof, nor any of their employees, makes any warranty, express or implied, or assumes any legal liability or responsibility for the accuracy, completeness, or usefulness of any information, apparatus, product, or process disclosed, or represents that its use would not infringe privately owned rights. Reference herein to any specific commercial product, process, or service by trade name, trademark, manufacturer, or otherwise does not necessarily constitute or imply its endorsement, recommendation, or favoring by the United States Government or any agency thereof. The views and opinions of authors expressed herein do not necessarily state or reflect those of the United States Government or any agency thereof.

This report has been reproduced directly from the best available copy.

Available to DOE and DOE contractors from the Office of Scientific and Technical Information, P.O. Box 62, Oak Ridge, TN 37831; prices available from (615) 576-8401, FTS 626-8401.

Available to the public from the National Technical Information Service, U.S. Department of Commerce, 5285 Port Royal Rd, Springfield, VA 22161. 


\title{
REACTOR ENGINEERING DESIGN
}

KEYWORD

Technical

Reactor

K Area

Fuel Inspection

K-15 REVIEWING
OFFICIAL:

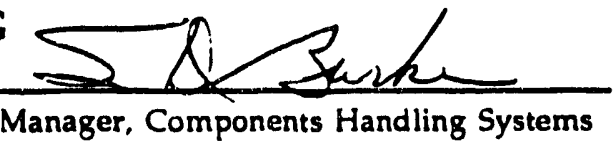

DATE:
RETENTION:

PERMANENT

CLASSIFIGATRPASSSIFIED

DOES NOT CONTAIN UNCLASSIFIED CONTROLLED NUCLEAR INFOAMATION

Roviewing

Offlcial:

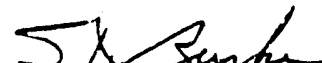

(Mamopna Tille)

\section{P-11/K-15 RE-INSPECTION STANDARDS}

\author{
BY: J. J. BANKS
}

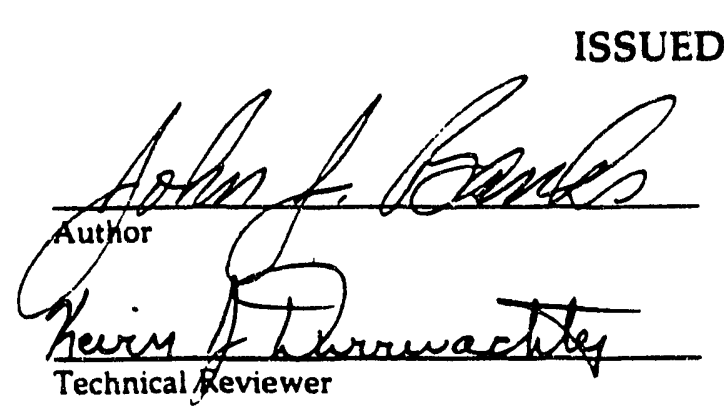

25: August 1992

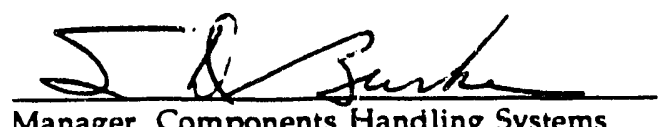

Manager, Components Handling Systems
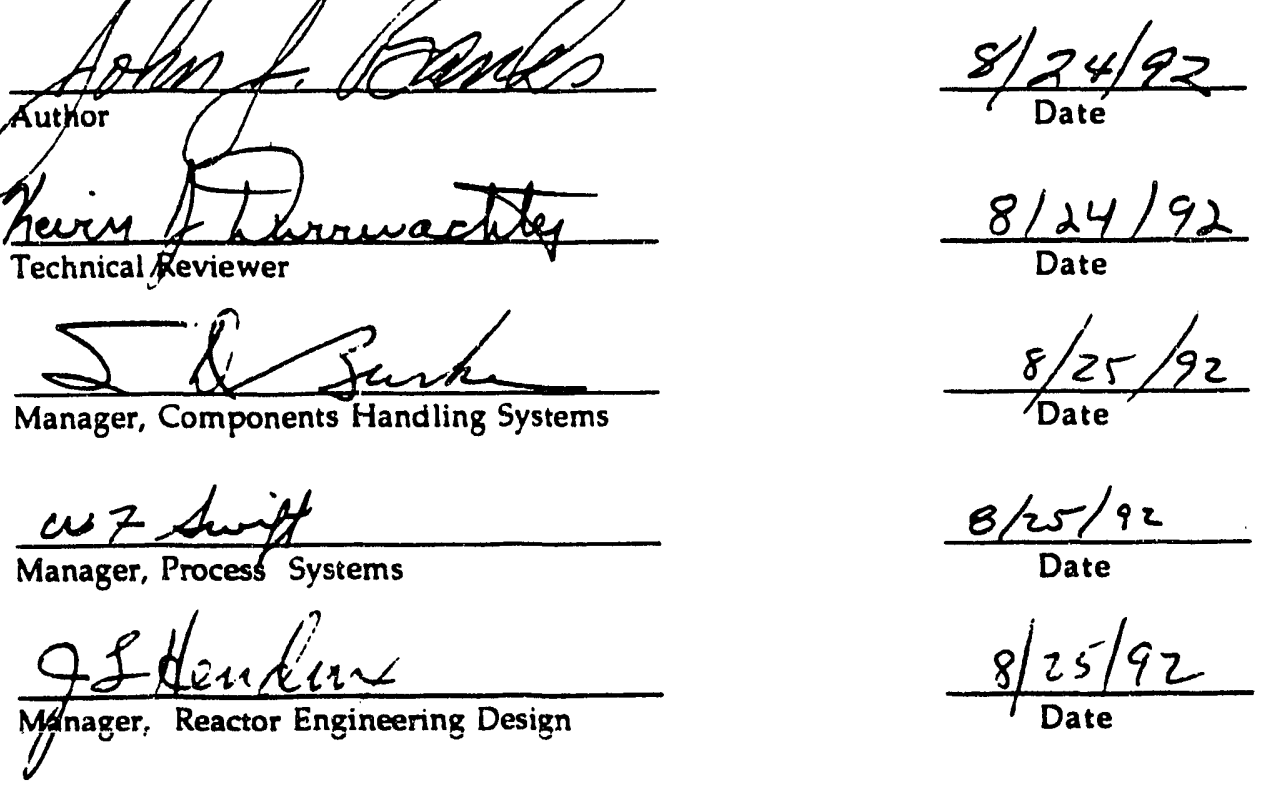


\section{Table Of Contents}

Section Title $\quad \underline{\text { Page }}$

Executive Summary............................................................................................... 1

Introduction................................................................................................. 1

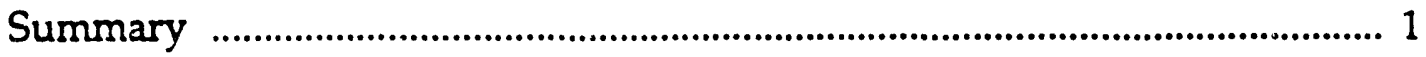

Discussion

Mark 22 Description........................................................................ 2

Inspection Standards and Potential Damage.............................. 3

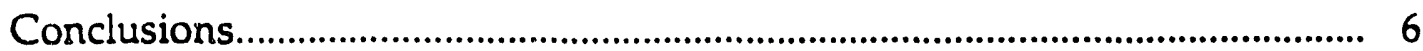

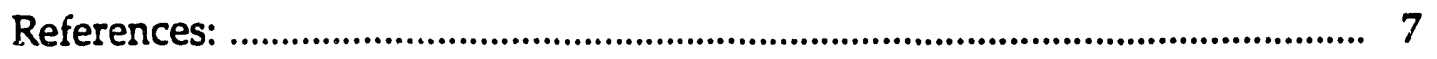

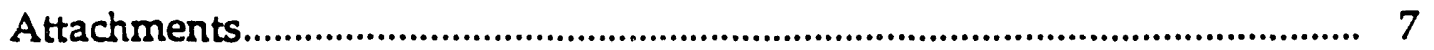




\section{REACTOR COMPONENTS P-11/K-15 RE-INSPECTION STANDARDS}

\section{EXECUTIVE SUMMARY:}

The Mark 22 assemblies previously charged to the P Reactor as the P-11 charge, but never irradiated, are stored in borated racks in Building $105-\mathrm{K}$ Assembly Area. The assemblies are stored inside aluminum cans into which they were placed and subsequently dried upon removal from the P-Reactor. Non-destructive examinations supplemented by destructive examination of a small number of these assemblies will be made to establish the acceptability of these assemblies for use as the $\mathrm{K}-15$ charge.

\section{INTRODUCTION:}

The P-11 Mark 22 assemblies were charged to the P-Reactor prior to the decision to permanently shutdown that reactor. The Mark 22 assemblies were subsequently removed from the $P$ Reactor, placed in aluminum cans, dried, and stored under the assumption that they could be used at a later date in the $\mathrm{K}$ Reactor. Current plans call for determination of the acceptability of these assemblies for use as the K-15 charge.

The P.11 charge met all inspection standards when charged to the $P$ Reactor. It is necessary to assess whether subsequent handling and storage have created damage which would prohibit their use. This report covers the re-inspection program.

\section{SUMMIARY:}

Of the seventy-nine inspections Mk-22 assemblies undergo during the fabrication and preparation process, only four may have been compromised as a result of subsequent handling in the reactor areas (Ref. 1). These four are related to surface defects of the concentrically assembled target and fuel tubes which form the Mk-22. The damage could be mechanical (dents, scratches, or gouges) or the result of corrosion. Mechanical damage could have occurred during the charging and discharging of $\mathrm{P}$ Reactor or during the storage process. Although the various environments to which the P-11 charge has been subjected (reactor moderator, air, deionized water, and canned storage) are not considered corrosive to aluminum, corrosive damage will be considered. 
The outer surface of the outer target tubes of all the P-11 assemblies will be inspected for mechanical damage and corrosive pitting. Analysis of the handling operations in the reactor areas shows that this is the only surface that has any significant probability of mechanical damage. The inner targets will be removed from $1 \%$ (5) of the assemblies and the inner surface of the inner fuel and the outer surface of the inner target will be inspected.

\section{DISCUSSION:}

The P-11 charge must be inspected prior to use in the $\mathrm{K}$ Reactor. Many of the inspection standards for certification of Mark 22's as acceptable for irradiation are performed during fabrication and assembly and cannot subsequently be repeated without destroying the assembly. In most cases, no reason exists for questioning the validity of the results of the original inspections.

A small number of the P-11 assemblies have been determined to be unacceptable for use in the K-15 charge for reasons unrelated to the inspection standards. They will be replaced. They have been subjected to the same environments, handling, and storage, as the other P-11 assemblies. Any assemblies to be destructively inspected will come from this group.

Special equipment (Focused Array Transducer System - "FATS"), capable of ultrasonic, through the assembly, inspection of all the surfaces, is being developed in SRTC. This system will be used for inspection of assemblies that show evidence of corrosion, or if detailed characterization of surface defects is required.

\section{Mark 22 Description: (Ref. 2 \& Attachment 2)}

Four concentric nested tubes, with appropriate top and bottom fittings, form each Mark 22 assembly. The nested tubes (from inside out) are: inner target, inner fuel, outer fuel, and outer target. The target tubes are lithium aluminum cores extruded with 1100 aluminum cladding. The fuel tubes are enriched uranium cores extruded with 8001 aluminum cladding. Longitudinal ribs are located on the inner target outer, the inner fuel outer, and the outer target inner, surfaces. There are no ribs on the outer fuel tubes. There are also ribs on the inner 
surface of the sleeve housings into which the Mark 22's are charged in the reactor. The ribs serve to center the tubes within the assembly and in the housing and form flow channels for coolant through the fuel assembly. All of the concentric tubes, except the inner target, are held together by tabs in the bottom fitting.

It is recognized that the cladding of the fuel tubes is more susceptible than the cladding of the target tubes to low temperature corrosion. However, the conditions to which the the P-11 assemblies were subjected was not corrosive to either alloy (Ref. 1). Therefore, all surfaces will be assumed to be equally at risk.

\section{Inspection Standards And Potential Damage:}

Design drawings specify seventy nine inspection criteria which Mark 22 assemblies must meet prior to being accepted for charging to a reactor. These are listed on Attachment 1. The P-11 assemblies, which originally met all of these standards, were subjected to operations with the potential for violating only the four criteria which apply to the mechanical condition of the surfaces of the various tubes in the Mark 22 assembly. The standards are consistent for all surfaces: no scratch or dent over the core of greater than 10 mils, over the end plugs of greater than 30 mils, and on the rib tips of greater than 50 mils. Although the four applicable standards address only mechanical defects, not corrosive pits, in the absence of other definitive, applicable standards, these will also be used for assessment of acceptability from corrosive damage.

Mechanical damage may have occurred from:

- Charging to the P Reactor,

- Discharging from the P Reactor, drying, and canning,

- Removal from the cans (Ref. 3) for inspection,

The outer surface of outer targets could have been damaged during the charging/discharging or canning and drying operations. $100 \%$ of the outer target outer surface will be inspected. No mechanism has been identified for mechanical 
damage to any other surfaces of the P-11 Mark 22 assemblies.

During the period from assembly through drying and storage, all of the P-11 Mark 22 assemblies, which includes all of the concentric tubes of each assembly, were subjected to the same environment and thus have the same potential for corrosive damage.

The P-11 assemblies were exposed to:

- Approximately 14 months to the moderator in the $P$ Reactor.

- Approximately 7 months to the atmosphere in the drained $\mathrm{P}$ Reactor.

- A nominal two hours to deionized water during the canning and drying operation.

- The atmosphere in the storage can for approximately 14 months.

Corrosive damage from exposure to the reactor moderator in the $\mathrm{P}$ Reactor is highly unlikely. Moderator chemistry was rigidly controlled to minimize corrosion (Ref: 1). Likewise, corrosive damage from exposure to the atmosphere during dry storage in the P Reactor is also highly unlikely. Air is not noted as highly corrosive to aluminum.

The fuel was removed from the dry $\mathrm{P}$ Reactor for canning using the following sequence:

1. Discharge the assembly in its sleeve housing,

2. Place the housing containing the Mark 22 in a tube filled with deionized water to provide water lubrication between the housing ribs and the outer target,

3. Remove the Mark 22 from its housing, allow it to drain, and place it into an aluminum storage can,

4. Install the can cap and gasket, and place in the drying frame,

5. Using heat and vacuum, dry the assembly in the can,

6 . Move the can containing the dried Mark 22 to the borated racks in assembly $v$ ia the presentation point. 
7. Remove the cans containing the Mark 22 assemblies from the P Area borated racks, ship them to 105-K Assembly Area and store them in the $\mathrm{K}$ borated racks.

Corrosion resulting from the exposure to deionized water during the removal of the assemblies from their associated sleeve housings, prior to canning and drying, is improbable. The time during which the assemblies were in the deionized water was only a few hours, and deionized water is not highly corrosive to aluminum.

Analysis for corrosive damage as the result of residual deionized water left in the cans after the drying process indicates minimal risk. The assemblies in the cans were heated and vacuum dried in the horizontal position. Tests conducted using dummy Mark 22 assemblies, prior to the drying of the P. 11 assemblies, validated this procedure. No water is believed to be in the cans. The cans were transferred from the reactor room to the final storage and assembly areas in the vertical position. If water was left in a can it would have drained to the bottom of the can. When the cans were subsequently placed in borated racks, in the horizontal position, any water which had drained from an assembiy would have collected in the lower arc of the ID of the can and acted primarily upon the outer surface of the outer target.

The outer surface of the outer target of all P-11 assemblies will be examined for evidence of corrosive damage. Additionally, the inner target outer surface and the inner fuel tube inner surface from $1 \%(5)$ of the assemblies which have been determined to be unacceptable for use in $\mathrm{K}-15$ because of other reasons will be inspected for corrosion. Access to the inner fuel tube is accomplished by removal of the inner target and visually inspecting the inner fuel inner surface using a remote visual aid (camera).

Nonconformances noted during the inspection program will be dispositioned using Nonconformance Reports (NCR's).

If corrosive damage is noted during the visual inspections, additional isspections, utilizing special equipment (Focused 
Array Transducer System, "FATS") being developed by SRTC, will be considered. This equipment is expected to be capable of indicating, and characterizing, defects on any of the nested tubes of an assembly.

\section{CONCLUSIONS:}

1. Only four of the required inspection standards for Mark 22 assemblies might have been compromised.

1. The P-11 Mark 22. assemblies were subjected to conditions or operations which could have caused mechanical damage to only the outer surface of the outer target tubes.

2. $100 \%$ of the P-11 Mark 22 assembly's outer target outer surfaces will be inswected to certify that they meet the inspection standards.

3. Corrosive damage to the P-11 mark 22 assemblies is highly unlikely. The potential for corrosive damage to the surfaces of the various target and fuel tubes which are components of Mark 22 assemblies was consistent during the time in the $P$-Reactor, and subsequently during discharge from the $P$-Reactor, and drying and storage of the assemblies. The inner targets will be removed from $1 \%(5)$ of the assemblies and their outer surface and the inner surface of the corresponding inner fuel tubes will be inspected to assess corrosive damage.

4. The standards for acceptance of Mark 22 assemblies as related to mechanical damage are appropriate for use as standards for assessment of corrosive damage.

5. The NCR process will be used to document and disposition individual tubes as well as the P-11 charge for use as the $\mathrm{K}-15$ charge.

6. The FATS system, if successfully demonstrated as capable of detecting and characterizing defects on the nested Mark 22 tubes, will be used for additional non-destructive examinations, if the need is indicated by the results of the P-11 inspection data. 


\section{REFERENCES:}

1. SRT-MTS-92-0371, Technical Bases For Re-inspection Criteria For The P-11/K-15 Charge (U), G.R. Caskey, Jr., J.P. Howell, \& M.R. Louthan, Jr., 8/14/92

2. Drawing ST-MDX-5-900216, Mark 22 Assembly.

3. Drawing ST-MDX5-10081, Storage Can For Mark-22 Fuel Assembly.

\section{ATTACHMENTS:}

1. Mark 22 Inspection Points

2. Mark 22 Assembly Cross-section 


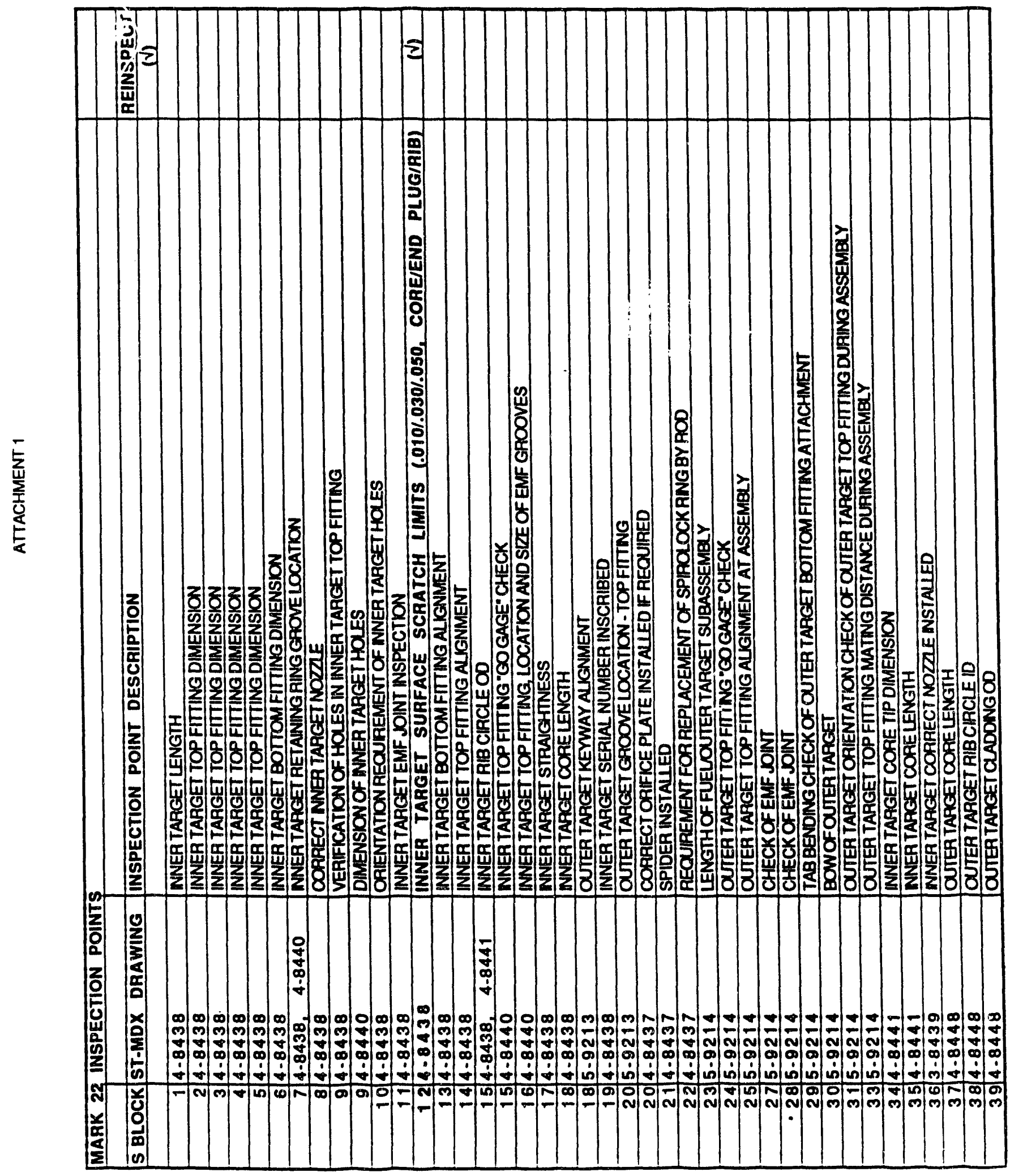




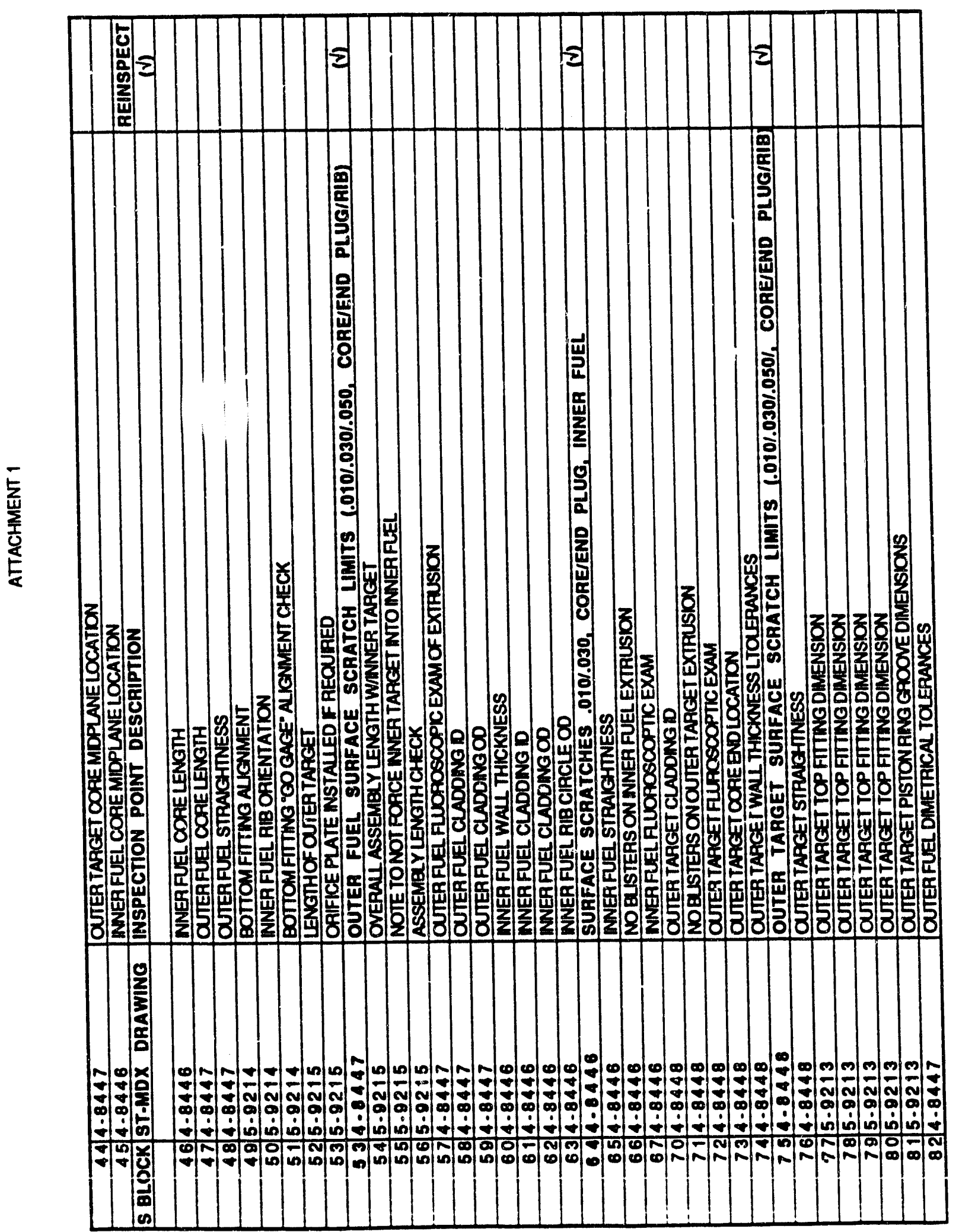

禺 


\section{ATTACHMENT 2}

\section{MARK 22 ASSEMBLY CROSS-SECTION}

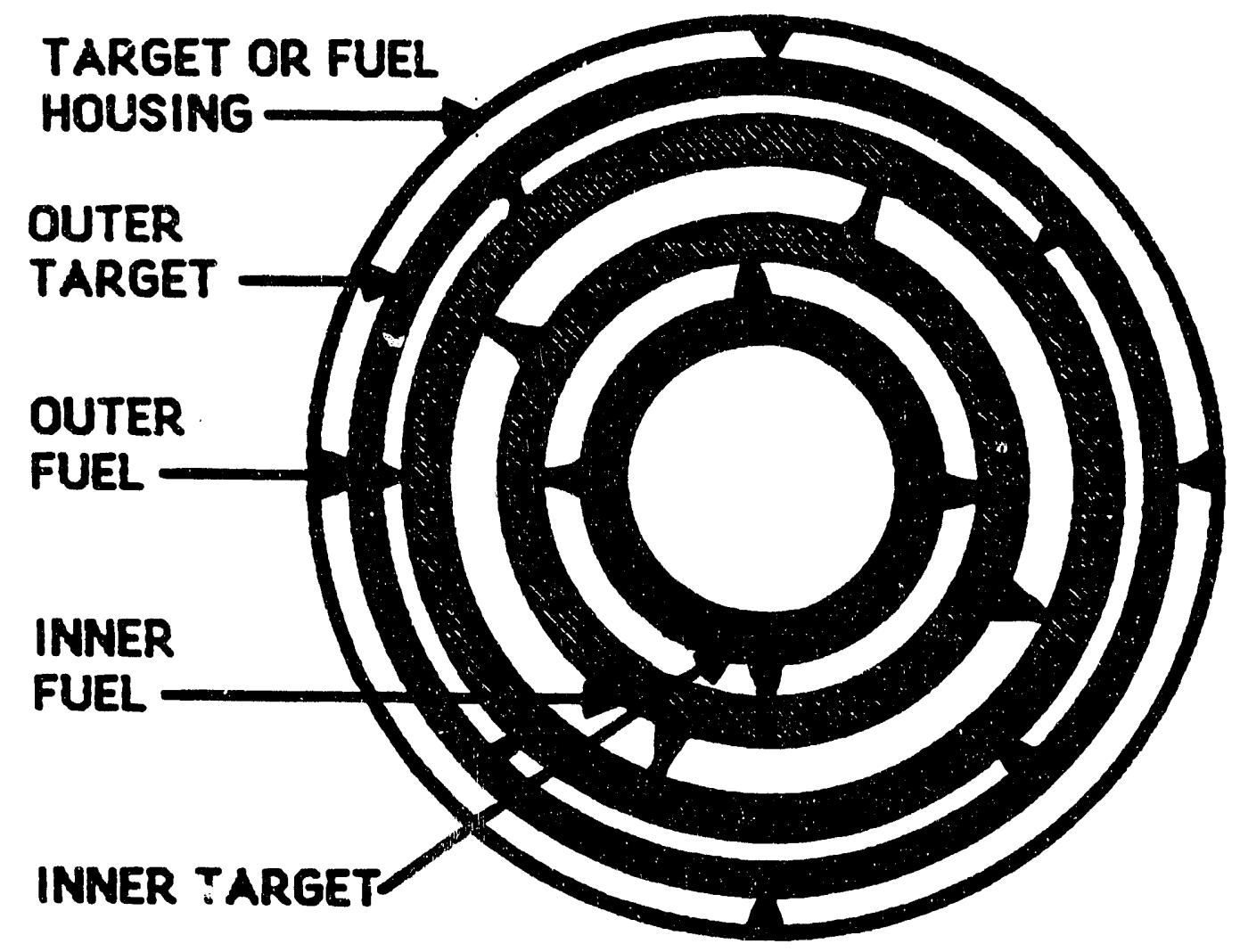



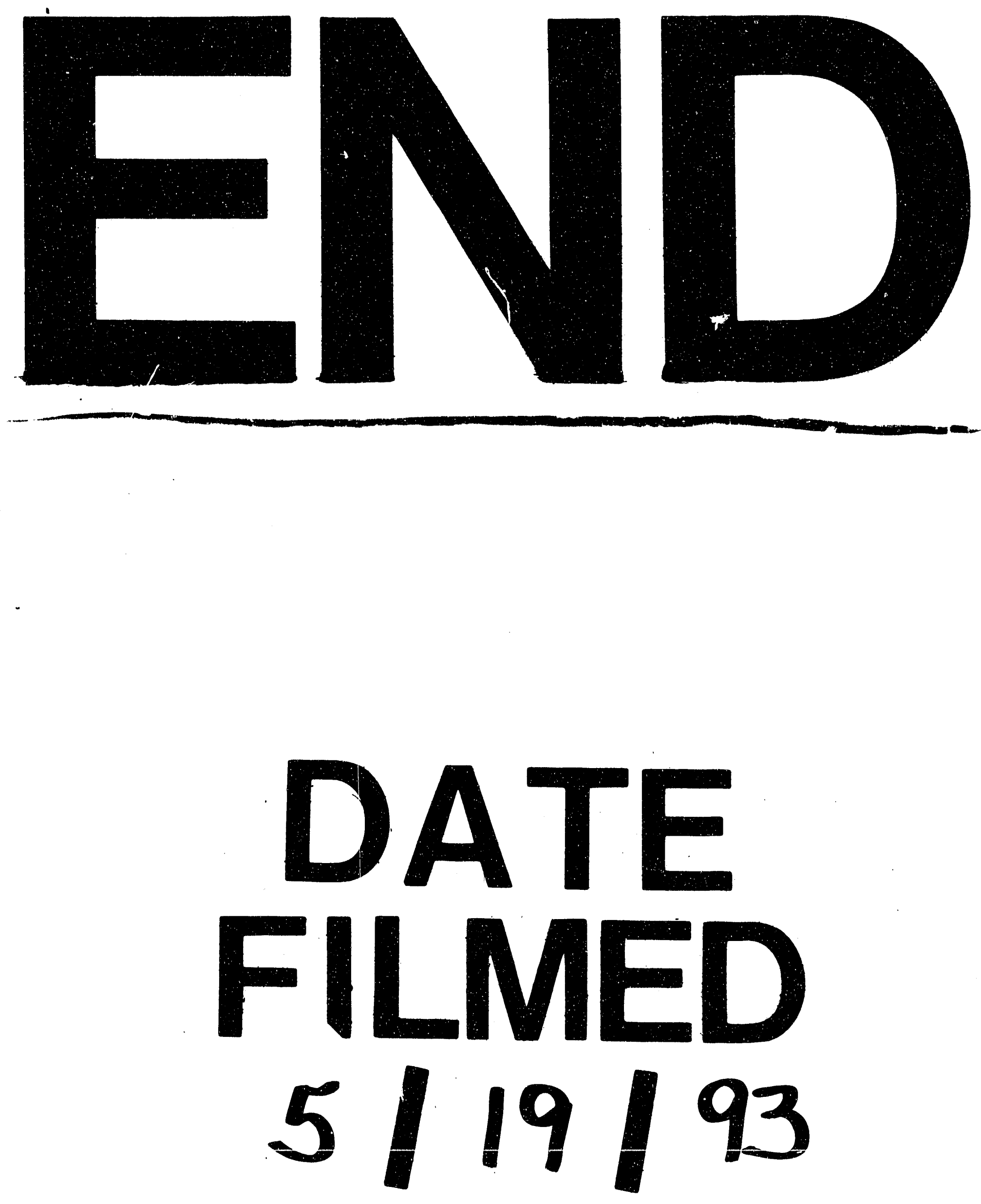
